\title{
Which accelerator will be next?
}

\begin{abstract}
The possibility that the Superconducting Super Collider will be cancelled, or at least seriously delayed, and impending developments in Europe, suggest the time has come for the United States to join CERN at Geneva.
\end{abstract}

As with much that happens in the US Congress, last month's defeat in the House of Representatives of the proposal to continue supporting the Superconducting Super Collider (SSC) does not imply finality. The Senate this week may begin to lay the groundwork for a compromise with the House from which SSC may yet rise like a phoenix. But this is only the first of half-a-dozen annual battles the accelerator's supporters will have to fight before the machine is built. The chance that the SSC will survive all of them cannot be high. Although the passage of time (and the spending of dollars) will make outright cancellation seem that much more galling, alarm about the federal deficit could make even that palatable. A contribution to the cost from Japan of $\$ 1.5$ billion or thereabouts could make a decisive difference in Washington, but the Japanese high-energy physics community has set its heart on different things (see page 266).

That is why the world's high-energy physics community, fond of boasting (justly) that it is the best-integrated of all, should seize this chance to reconsider its future. In Europe, high-energy physicists have long acknowledged that new accelerators are far too expensive (and short-lived in competitive usefulness) to be supported nationally. (That is not to diminish the importance of Germany's DESY at Hamburg - a national facility put to international use.) The same principle seems to be accepted in the United States, but as an unwelcome stratagem for the future, for "the accelerator after next". What will happen if the next accelerator, SSC, is never finished?

What this means is that the high-energy physics community internationally should recognize that the time for an international accelerator-building venture is not tomorrow but today, in the here and now. As good luck will have it, the present is full of opportunities that will not recur this century. Later this year, the council of the European high-energy physics laboratory (CERN) at Geneva will have to decide in principle to build the its Large Hadron (proton-antiproton) Collider (LHC) in the tunnel of the electron-positron collider called LEP. The same council will have to choose a new director for the laboratory, in succession to Dr Carlo Rubbia, who will be leaving at the end of 1993 .

The CERN machine will not be as powerful, in maximum energy and luminosity, as SSC is planned to be, but it should cover much of the same ground and should be operating sooner. In an orderly world, LHC would have been run for a little while before the final decisions were made about SSC. In the event, when it has run for a little while, it may become clear that a different kind of accelerator, perhaps two oppositely directed linear accelerators of electrons, would be the best next step, in which case both the US Congress and the taxpayers whose funds it spends may feel bilked. These two possibilities illustrate the perpetual difficulty of recruiting financial support for high-energy physics. Orderliness certainly saves money, measured as spending per decade, but postpones discovery and encourages the dispersal of research and design teams. Too much of it would give highenergy physics grounds for fearing that their ambitions would be steadily attenuated by budget constraints. But too much competitiveness can lead to mistakes, with the consequence that the flow of funds dries up altogether.

So why not put together the hesitancy of the Congress, the opportunity of the LHC and the impending change of management at CERN to form a true international partnership for the design, construction and operation of the "next accelerator"? At the very least, the United States should apply for membership of CERN. Japan would no doubt willingly follow suit, if only to escape the unseemly (and eventually corrosive) pressure to which it has been subjected by the United States over recent months. And the world's taxpayers, so far amazingly tolerant of the demands of high-energy physics, may for a little longer be persuaded that the ambitions of high-energy physics are every bit as important and exciting as they are described.

\section{Unloved academics}

British university teachers, already badly paid, have been done out of a pay-rise they deserved.

THE belief that academics are a gang of layabouts, not deserving of the rewards others enjoy, is deeply entrenched among British governments. Much of Mrs (as she was) Margaret Thatcher's animus against British universities and those working in them sprang from these deep wells. But the change of government has not changed attitudes. Last Thursday, the government confirmed the rumours it had started that it would not allow the salaries of academics to increase by the 7 per cent agreed between the university vicechancellors (otherwise, 'presidents' or 'rectors') and the labour unions, but would instead insist on only 5 per cent. The vice-chancellors are right to say that the incident raises the question of who runs British universities, which are 